\title{
Novel cerebral physiologic monitoring to guide low-flow cerebral perfusion during neonatal aortic arch reconstruction
}

Dean B. Andropoulos, MD

Stephen A. Stayer, $M^{\mathrm{a}}$

E. Dean McKenzie, MD ${ }^{b}$

Charles D. Fraser, Jr, MD, FACS ${ }^{b}$
From the Divisions of Pediatric Cardiovascular Anesthesiology ${ }^{\mathrm{a}}$ and Congenital Heart Surgery, 'Texas Children's Hospital and Baylor College of Medicine, Houston, Tex.

Financial support was solely from departmental and institutional sources.

Read at the Eighty-second Annual Meeting of The American Association for Thoracic Surgery, Washington, DC, May 5-8, 2002.

Received for publication April 8, 2002; revisions requested May 15, 2002; revisions received May 22, 2002; accepted for publication July 8, 2002.

Address for reprints: Dean B. Andropoulos, MD, 6621 Fannin St, WT19345H, Houston, TX 77030-2399 (E-mail: dra@bcm.tmc.edu).

J Thorac Cardiovasc Surg 2003;125:491-9

Copyright $\odot 2003$ by The American Association for Thoracic Surgery

0022-5223/2003 $\$ 30.00+0$

doi: $10.1067 / \mathrm{mtc} .2003 .159$
Objective: This study was undertaken to describe the combined measurement of cerebral blood flow velocity and cerebral oxygen saturation as a guide to bypass flow rate for regional low-flow perfusion during neonatal aortic arch reconstruction.

Methods: Data were prospectively collected from 34 patients undergoing neonatal aortic arch reconstruction with regional low-flow perfusion. Cerebral oxygen saturation and blood flow velocity were measured by near-infrared spectroscopy and transcranial Doppler ultrasonography, respectively, throughout cardiopulmonary bypass. After cooling to $17^{\circ} \mathrm{C}$ to $22^{\circ} \mathrm{C}$, baseline values of cerebral oxygen saturation and blood flow velocity were recorded during full-flow bypass. Regional low-flow perfusion was instituted for aortic arch reconstruction, and bypass flow rate was adjusted to maintain cerebral oxygen saturations and blood flow velocities within $10 \%$ of baseline recorded during cold full-flow bypass. Cerebral oxygen saturations and blood flow velocities were recorded again after repair during full-flow hypothermic bypass. Bypass flow during regional low-flow perfusion was recorded, as were arterial pressure and blood gas data. One-way repeated measures analysis of variance was used to determine differences in values during regional low-flow perfusion relative to baseline and after perfusion.

Results: A mean bypass flow of $63 \mathrm{~mL} /(\mathrm{kg} \times \min )$ was required to maintain cerebral oxygen saturations and blood flow velocities within $10 \%$ of baseline. Mean arterial pressure had a poor correlation with the required bypass flow rate $\left(r^{2}=\right.$ 0.006 by linear regression analysis). Fourteen of 34 patients had a cerebral oxygen saturation of $95 \%$ during regional low-flow perfusion, placing them at risk for cerebral hyperperfusion if the cerebral oxygen saturation had been used alone to guide bypass flow. Pressure was detected in the umbilical or femoral artery catheter (mean $12 \mathrm{~mm} \mathrm{Hg}$ ) in all patients during regional low-flow perfusion.

Conclusions: Cerebral blood flow velocity, as determined by transcranial Doppler ultrasonography, adds valuable information to cerebral oxygen saturation data in guiding bypass flow during regional low-flow perfusion. Its most important use may be prevention of cerebral hyperperfusion during periods with high near-infrared spectroscopic saturation values.

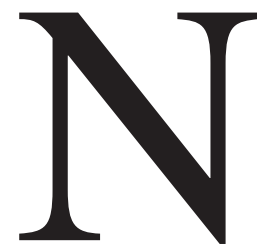
eonatal aortic arch reconstruction requires a bloodless operating field for optimum surgical precision. Traditionally this has been performed with deep hypothermic circulatory arrest (DHCA) for periods as long as 60 minutes, or even longer for such complex procedures as the Norwood operation for hypoplastic left heart syndrome (HLHS). Recent clinical evidence has demonstrated that periods of DHCA of 45 to 60 minutes or longer are associated with significant 
risk of neurologic injury. ${ }^{1,2}$ Cardiopulmonary bypass techniques have been developed to minimize periods of DHCA. ${ }^{3,4}$ One such technique is regional low-flow perfusion (RLFP), 5,6 in which only the brain and upper body are perfused, allowing a bloodless field for aortic reconstruction and either eliminating DHCA or limiting it to short periods.

Near-infrared spectroscopy (NIRS) measures the oxygen saturation $\left(\mathrm{SO}_{2}\right)$ of hemoglobin in the blood vessels of the frontal cerebral cortex. It may provide an estimate of cerebral blood volume, the cerebral blood volume index (CBVI), and functions under a wide variety of conditions, including hypothermic cardiopulmonary bypass and DHCA in infants and children. ${ }^{7,8}$ NIRS has been used to guide bypass flow during RLFP, with the goal of matching CBVI during RLFP to baseline CBVI on full bypass flow to the whole body. ${ }^{6}$ Possible shortcomings of using NIRS alone are that it is a trend monitor only. It does not measure absolute $\mathrm{So}_{2}$, and relative to jugular venous bulb-measured $\mathrm{So}_{2}$, it is less accurate at the high and low ends of the scale. ${ }^{9}$ Commercially available cerebral oximeters read a maximum high value of $95 \%$, potentially exposing the patient to the risk of cerebral hyperperfusion at high cerebral $\mathrm{So}_{2}$ values. Finally, CBVI has not been independently validated as a true measure of cerebral blood volume or blood flow.

Pulsed-wave transcranial Doppler ultrasonography (TCD) is a sensitive indicator of cerebral blood flow (CBF) velocity (CBFV). ${ }^{10}$ It has been used for neonatal heart surgery to guide flow rate during low-flow bypass, ${ }^{11}$ as a monitor of adequacy of arterial and venous bypass cannula placement, and for the detection of cerebral emboli in infants and children. ${ }^{12}$ The purpose of this study is to describe the addition of CBFV, as measured by TCD, to cerebral cortical $\mathrm{SO}_{2}$, as measured by NIRS, as a guide to bypass flow during RLFP during neonatal aortic arch reconstruction.

\section{Methods}

After institutional review board approval was obtained, infants undergoing aortic arch reconstruction were studied. Patients undergoing the Norwood operation for HLHS or a variant and those undergoing aortic arch advancement for interrupted aortic arch or severe arch hypoplasia were studied if a period of RLFP was planned.

The anesthetic technique consisted of high-dose fentanyl (100$200 \mu \mathrm{g} / \mathrm{kg}$ ), midazolam (0.3-1.0 mg/kg), and pancuronium bromide or vecuronium bromide for muscle relaxation. Low-dose isoflurane $(<1 \%)$ was used to supplement the anesthetic before bypass. Isoflurane at up to $2 \%$ was used on bypass for vasodilation and was always discontinued before rewarming.

Arterial pressure monitoring consisted of an umbilical or femoral arterial catheter. In addition, a catheter was placed in the left radial or brachial artery for patients undergoing the Norwood operation and in the right radial or brachial artery for patients undergoing aortic arch advancement. Two arterial catheters were used to monitor both the cerebral and distal aortic pressures during
RLFP and to assess the adequacy of repair after aortic arch advancement.

Cerebral physiologic monitoring included NIRS (INVOS 5100; Somanetics Corporation, Troy, Mich) to measure cerebral $\mathrm{So}_{2}$. This method uses near-infrared light at 730- and 810-nm wavelengths to measure the absorption spectra of oxyhemoglobin and deoxyhemoglobin in the frontal cerebral cortex. A shallow detector subtracts light absorbed by the skull and soft tissues, and a deep detector measures light absorbed by an area in the frontal cortex in the light path. The total and oxygenated hemoglobin concentrations are measured, and this information is entered into an algorithm which assumes that $25 \%$ of the blood volume is arterial and $75 \%$ is venous; percentage cerebral $\mathrm{So}_{2}$ is displayed as a result. In addition, an index of total hemoglobin concentration is displayed, which can be used as a surrogate measure of relative cerebral blood volume (CBVI) if hemoglobin remains constant. The sensor was applied to the forehead just to the right of midline.

Pulsed-wave TCD (EME Companion; Nicolet Biomedical Inc, Madison, Wis) of the right middle cerebral artery was used to measure $\mathrm{CBFV}$. A 2-MHz probe was placed over the right temporal area or over the anterior fontanelle, and settings were adjusted until a maximal antegrade CBFV signal was obtained. The mean CBFV was displayed and recorded.

For patients undergoing the Norwood operation, bypass was initiated through an $8 \mathrm{~F}$ or $10 \mathrm{~F}$ aortic cannula inserted into the distal end of a 3 or $3.5 \mathrm{~mm}$ polytetrafluoroethylene graft, ${ }^{*}$ with the proximal end anastomosed into the distal right innominate artery or proximal right subclavian artery. Monitoring of CBFV during innominate artery occlusion ensured baseline $\mathrm{CBF}$. The remaining patients had a polytetrafluoroethylene graft* used for systemic arterial flow in the case of an undersized ascending aorta or standard cannulation of the ascending aorta with a $10 \mathrm{~F}$ cannula if the vessel was of adequate size. Patients with interrupted aortic arch had a second arterial cannula placed in the patent ductus arteriosus to perfuse the lower body. Patients with aortic arch hypoplasia were perfused with one or two aortic cannulas, depending on the anatomy and severity of the arch obstruction. Single or bicaval venous cannulation was used, depending on the nature of the intracardiac lesions and the size of the patient.

Bypass was instituted at a flow of $150 \mathrm{~mL} /(\mathrm{kg} \times \mathrm{min})$. Phenoxybenzamine $(0.25 \mathrm{mg} / \mathrm{kg})$ was administered to all patients undergoing Norwood procedures on initiation of bypass. Phenoxybenzamine $(0.25-1 \mathrm{mg} / \mathrm{kg})$ or phentolamine hydrochloride (INN phentolamine, $0.3-1 \mathrm{mg} / \mathrm{kg}$ ) was administered to all other patients on bypass to achieve a mean arterial pressure of 30 to $40 \mathrm{~mm} \mathrm{Hg}$ at a minimum flow of $150 \mathrm{~mL} /(\mathrm{kg} \times \mathrm{min})$ throughout the duration of bypass. Extracorporeal cooling to a nasopharyngeal temperature of $17^{\circ} \mathrm{C}$ to $22^{\circ} \mathrm{C}$ was achieved during no less than 20 minutes, during which time additional dissection of the aorta and brachiocephalic vessels was performed. The target hematocrit was $25 \%$ during the period of hypothermia. The $\mathrm{pH}$-stat blood gas strategy was used during all phases of the bypass period. Blood gas values were measured every 10 to 20 minutes, and sweep gas flow was adjusted to achieve target temperature-corrected $\mathrm{PCO}_{2}$ of 30 to 40 $\mathrm{mm} \mathrm{Hg}$ and $\mathrm{pH}$ of 7.40 to 7.50. Inspired carbon dioxide was added to the sweep gas as necessary to achieve these values. An aortic

*Gore-Tex vascular graft, registered trademark of W.L. Gore \& Associates, Inc, Flagstaff, Ariz. 
crossclamp was placed, and crystalloid cardioplegia was administered. For patients undergoing Norwood procedures, a brief period $(<10$ minutes $)$ of circulatory arrest was used during atrial septectomy. Then RLFP was used for the aortic reconstruction, as follows. Snares were placed around the bases of the right innominate, left common carotid, and left subclavian arteries and around the descending thoracic aorta distal to the coarctation. Perfusion was then instituted through the polytetrafluoroethylene graft to the cerebral vessels only during the aortic reconstruction. Bypass flow was adjusted until the CBFV was within $10 \%$ of baseline recorded at full-flow whole-body bypass at $17^{\circ} \mathrm{C}$ to $22^{\circ} \mathrm{C}$. At the completion of the aortic reconstruction, the aortic cannula was placed in the neoaorta during a brief period of DHCA (1-2 minutes). DHCA was not otherwise used for patients undergoing the Norwood procedure unless the operation was performed for lesions other than HLHS and considerable intraoperative decisions were being made on the basis of intracardiac exploration.

For patients undergoing aortic arch advancement, RLFP was used for the dissection and extensive mobilization of the descending thoracic aorta after ligation and division of the isthmus to avoid excessive cerebral perfusion, again with flow adjusted to match baseline CBFV. This was followed in some cases by a period of 20 to 30 minutes of DHCA during the anastomosis of the aorta. Thus two additional vessels, the left subclavian artery and left carotid artery, were perfused during this form of RLFP. In some cases DHCA for this procedure was completely avoided by performing the aortic arch advancement with RLFP alone, depending on the anatomy and at the surgeon's discretion.

Intracardiac defects were repaired after aortic reconstruction during hypothermic full-flow cardiopulmonary bypass at a minimum flow of $150 \mathrm{~mL} /(\mathrm{kg} \times \mathrm{min})$. Low-flow full-body bypass or DHCA was used only when it was not otherwise possible to achieve a sufficiently bloodless operating field.

The following data were collected: patient age, patient weight, diagnosis, operation, bypass time, aortic crossclamp time, DHCA time, and RLFP time. Data on bypass were collected at three intervals: during full-flow whole-body bypass at deep hypothermic temperatures $\left(17^{\circ} \mathrm{C}-22^{\circ} \mathrm{C}\right)$ immediately before RLFP, during RLFP at $17^{\circ} \mathrm{C}$ to $22^{\circ} \mathrm{C}$ after adjustment of bypass flow rate to achieve CBFV values within $10 \%$ of baseline, and within 5 minutes after aortic reconstruction during full-flow bypass to the whole body at $17^{\circ} \mathrm{C}$ to $22^{\circ} \mathrm{C}$ after steady-state cerebral $\mathrm{So}_{2}$ and $\mathrm{CBFV}$ values were achieved before rewarming. Data collected included bypass flow rate, cerebral $\mathrm{So}_{2}$ and $\mathrm{CBFV}$ values, mean pressure in the radial or brachial and umbilical or femoral arteries, temperature-corrected blood gas values, hematocrit, calculated base excess, and plasma lactate (available for the final 19 patients in the study). One-way repeated measures analysis of variance (SPSS Inc, Chicago, Ill) was used to compare values between the three time periods. The Bonferroni test was used for post hoc pairwise comparisons of the changes in parameters during the three study time periods. Linear regression analysis was used to correlate bypass flow during RLFP with mean arterial pressure measured in the radial artery, cerebral $\mathrm{So}_{2}$, and CBFV. The $t$ test was used to compare RLFP times, flow rates, and CBFV between patients who underwent Norwood procedures and those who did not. Outcome follow-up consisted of a medical record review of all available information for the following: 30-day postoperative or in-hospital mortality; late mortality after 30 days, and neurologic deficits recorded by the patient's primary cardiologist during postoperative outpatient clinic visits.

\section{Results}

Thirty-four patients were studied between January 2001 and February 2002. The patient diagnoses and operations are presented in Table 1. Thirteen patients underwent the Norwood operation, 13 underwent an aortic arch advancement procedure, and 8 underwent repair of interrupted aortic arch. Patient demographic characteristics and bypass times are presented in Table 2. Cerebral $\mathrm{So}_{2}$ before incision during steady-state hemodynamics at $36^{\circ} \mathrm{C}$ to $37^{\circ} \mathrm{C}$ was $60 \% \pm$ $11 \%$, and mean CBFV was $21 \pm 6 \mathrm{~cm} / \mathrm{s}$. RLFP times ranged from 6 to 158 minutes, and DHCA times ranged from 0 to 66 minutes. Six patients underwent no DHCA. The period of RLFP did not differ between patients who underwent Norwood procedures and those who did not $(62 \pm 14$ minutes vs $43 \pm 36$ minutes, respectively, $P=$ .078).

The intraoperative perfusion and cerebral physiologic monitoring data are presented in Table 3. During RLFP, mean arterial pressure in the umbilical or femoral artery ranged from 4 to $21 \mathrm{~mm} \mathrm{Hg}$. The mean bypass flow rate necessary to maintain baseline $\mathrm{CBFV}$ was $63 \mathrm{~mL} /(\mathrm{kg} \times$ $\mathrm{min})$, with a range of 24 to $94 \mathrm{~mL} /(\mathrm{kg} \times \mathrm{min})$. This represents a mean of $42 \%$ of normal full-flow bypass. The RLFP flow rate of patients who underwent Norwood procedures was not different from that of those who did not $(59 \pm 18$ vs $66 \pm 19 \mathrm{~mL} /[\mathrm{kg} \times \mathrm{min}]$, respectively, $P=$ .329). This flow rate had a poor correlation with pressure measured in the radial or brachial artery $\left(r^{2}=0.006\right.$ by linear regression analysis; Figure 1). Correlations between RLFP rate and CBFV and between RLFP rate and cerebral $\mathrm{So}_{2}$ are presented in Figure 2. Both the calculated base deficit and the lactate concentration increased during the RLFP period. CBFV during RLFP did not differ for patients perfused through the innominate artery only with brachiocephalic vessel snares in place with the aortic arch opened (Norwood and Damus-Kaye-Stansel procedures) and those perfused through the intact aortic arch for arch advancement $(23 \pm 9$ vs $22 \pm 9 \mathrm{~cm} / \mathrm{s}$, respectively, $P=.55)$.

The 30-day postoperative mortality was 1 of 34 patients, or $2.9 \%$. One patient died on postoperative day 1 , a neonate with Shone complex variant with hypoplastic aortic valve and ascending aorta and severe endocardial fibroelastosis of the left ventricle. He underwent the Norwood operation, had low cardiac output syndrome develop that was unresponsive to escalating inotropic therapy, and died after a probable pulmonary hypertensive crisis during weaning from inhaled nitric oxide. Late mortality after 30 days has consisted of 1 patient who had undergone a Norwood operation for HLHS who died at the age of 4 months after admission to the 
TABLE 1. Patient diagnoses and operations ( $n=34$ )

\begin{tabular}{|c|c|c|c|}
\hline Diagnosis & Secondary diagnosis & Operation & Additional procedures \\
\hline HLHS ( $n=12)$ & & Norwood operation & \\
\hline $\begin{array}{l}\text { Shone complex with LV } \\
\text { endocardial } \\
\text { fibroelastosis }(n=1)\end{array}$ & & Norwood operation & \\
\hline \multirow[t]{9}{*}{$\mathrm{IAA}(\mathrm{n}=8)$} & & Repair IAA & \\
\hline & Type A: D-TGA, DORV & & Arterial switch, repair DORV \\
\hline & Type A: multiple VSDs & & PA banding \\
\hline & Type A: DORV & & PA banding \\
\hline & Type A: VSD & & VSD closure \\
\hline & Type B: unbalanced CAVC, AS & & $\begin{array}{l}\text { Damus-Kaye-Stansel } \\
\text { procedure }\end{array}$ \\
\hline & Type B: VSD, subaortic stenosis & Subaortic resection, VSD closure & \\
\hline & Type B: AP window, ASD & & AP window, ASD \\
\hline & Type B: truncus type III, ASD & & Rastelli repair of truncus \\
\hline \multirow{14}{*}{$\begin{array}{l}\text { Transverse aortic arch } \\
\text { hypoplasia }(n=13)\end{array}$} & & Aortic arch advancement & \\
\hline & CoA, AS, multiple VSDs & & Aortic valvotomy, PA banding \\
\hline & CoA, ASD & & ASD closure \\
\hline & $\begin{array}{l}\text { Shone variant-AS, subaortic } \\
\text { stenosis, CoA }\end{array}$ & & Aortic valvotomy \\
\hline & CoA, VSD & & PA banding \\
\hline & Shone variant-CoA, VSD & & VSD repair \\
\hline & D-TGA, VSD, CoA, ASD, PDA & & $\begin{array}{l}\text { Arterial switch; VSD, ASD, } \\
\text { and PDA repair; RVOT } \\
\text { resection }\end{array}$ \\
\hline & $\begin{array}{l}\text { Shone variant-hypoplastic MV, } \\
\text { AV, LV; LV outflow tract } \\
\text { obstruction; CoA }\end{array}$ & & $\begin{array}{l}\text { Damus-Kaye-Stansel } \\
\text { procedure }\end{array}$ \\
\hline & DORV, mitral stenosis, ASD & & Atrial septectomy, PA band \\
\hline & $\begin{array}{l}\text { Severe aortic arch stenosis and } \\
\text { aneurysm }\end{array}$ & & None \\
\hline & $\begin{array}{l}\text { Severe aortic arch hypoplasia with } \\
\text { near interruption, large PDA }\end{array}$ & & PDA ligation \\
\hline & $\begin{array}{l}\text { D-TGA, mitral atresia, LV } \\
\text { hypoplasia, CoA PDA, PFO }\end{array}$ & & $\begin{array}{l}\text { PA band, atrial septectomy, } \\
\text { PDA ligation }\end{array}$ \\
\hline & $\begin{array}{l}\text { Dextrocardia, single ventricle, } \\
\text { subaortic stenosis, AS, CoA }\end{array}$ & & $\begin{array}{l}\text { PA band, subaortic resection, } \\
\text { atrial septectomy }\end{array}$ \\
\hline & Shone variant-hypoplastic LV, MV & & Inspect MV \\
\hline
\end{tabular}

$L V$, Left ventricle; $I A A$, interrupted aortic arch; $D-T G A$, dextrotransposition of the great arteries; DORV, double-outlet right ventricle; VSD, ventricular septal defect; $P A$, pulmonary artery; $C A V C$, complete atrioventricular canal; $A S$, aortic stenosis; $A P$, aortopulmonary; $A S D$, atrial septal defect; $C O A$, coarctation of aorta; $P D A$, patent ductus arteriosus; $R V O T$, right ventricular outflow tract; $P D A$, patent ductus arteriosus; $M V$, mitral valve; $A V$, aortic valve; $P F O$, patent foramen ovale.

hospital for pneumonia. He had a cardiac arrest while on the ward and could not be resuscitated.

Neurologic follow-up has ranged from 1 to 11 months. One patient who had undergone complete repair of truncus arteriosus type III with interrupted aortic arch type A was admitted to the hospital at age the of 3 months with respiratory failure secondary to pneumonia and seizures. Seizures were secondary to a serum sodium concentration of $125 \mathrm{mmol} / \mathrm{L}$ from severe dehydration secondary to pyloric stenosis. The patient returned to baseline neurologic status without lateralizing findings and has had no further neurologic events. No other survivors had any abnormalities detected by standard clinical neurologic examination.

\section{Discussion}

RLFP is a modified perfusion technique that provides continuous cerebral perfusion during neonatal aortic arch reconstruction, minimizing or avoiding DHCA. NIRS has been described as a method to guide bypass flow. ${ }^{6}$ In this study we demonstrated that CBFV measurement provides additional information during RLFP to ensure adequate, but not excessive, CBF.

Although measurement of cerebral $\mathrm{SO}_{2}$ is a useful trend monitor, NIRS has shortcomings that make it important to have an independent, corroborating method to guide bypass flow during RLFP. First, clinically available NIRS monitors are unable to measure absolute cerebral $\mathrm{SO}_{2}$, because this 


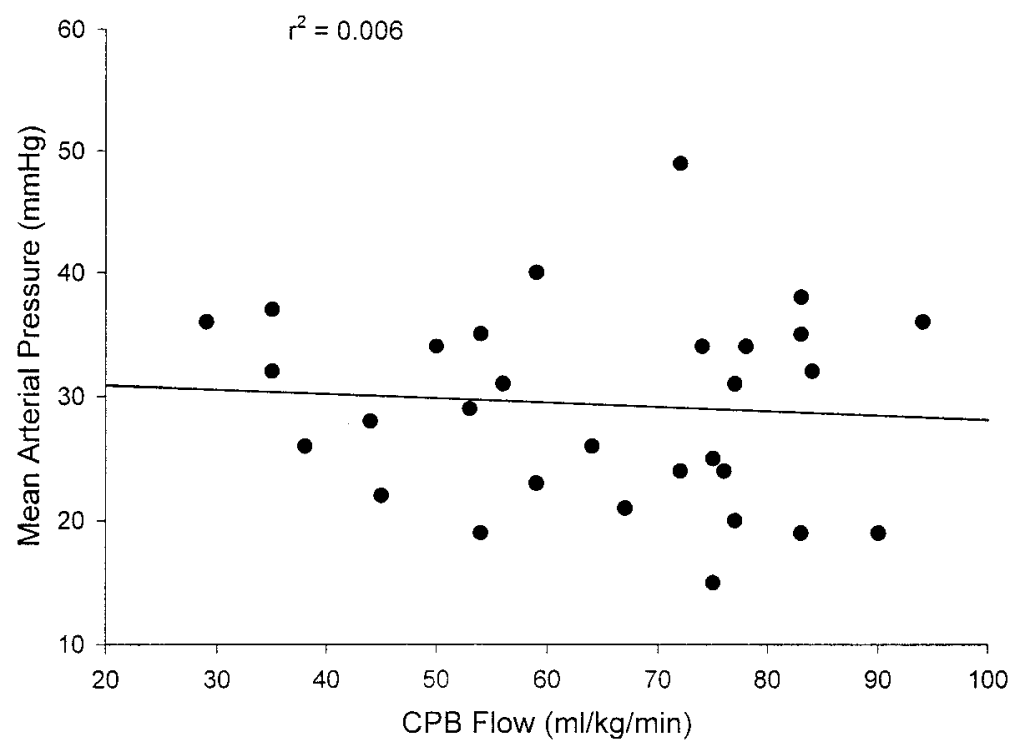

Figure 1. Mean arterial pressure during RLFP measured in radial or brachial artery versus cardiopulmonary bypass (CPB) flow rate necessary to achieve baseline cerebral $\mathrm{So}_{2}$ and $\mathrm{TCD}$ CBFV; $r^{2}=0.006$ by linear regression analysis.

would require measurement of the path length of the absorbed infrared light, ${ }^{13}$ which is not available on the Somanetics INVOS 5100 or the NIRO 500 NIRS monitor (Hamamatsu Photonics KK, Hananatsu City, Japan) used in previous descriptions of NIRS for RLFP. ${ }^{6,14}$ Second, cerebral $\mathrm{SO}_{2}$ measurement by NIRS depends on an algorithm assuming that $75 \%$ of the cerebral blood volume is venous blood and $25 \%$ is arterial. This assumption is based on adult data, does not account for patient variability, and has not been verified for pediatric patients. Finally, the Somanetics monitor displays a maximal cerebral $\mathrm{So}_{2}$ of $95 \%$. Many patients have extremely high cerebral $\mathrm{So}_{2}$ values during hypothermic bypass. Under these conditions the Somanetics NIRS monitor would only detect inadequate blood flow (desaturation) and not excessive CBF (hypersaturation). Fourteen of our 34 patients had a cerebral $\mathrm{SO}_{2}$ reading of 95\% during RLFP, potentially leaving them vulnerable to overcirculation. Six of these patients underwent perfusion to the innominate artery alone with the aortic arch opened and brachiocephalic vessel snares in place, and the other 8 underwent perfusion with the aortic arch intact. The potential dangers of excessive CBF during RLFP include cerebral edema and intracranial hemorrhage. Although there have been no reports of these complications from hypothermic bypass during cardiac surgery in neonates, even in premature infants, ${ }^{15}$ intracranial hemorrhage occurs frequently during extracorporeal membrane oxygenation for neonatal respiratory and cardiac failure. ${ }^{16}$ This complication is associated with the use of high extracorporeal membrane oxygenation flows accompanied by elevated mean arterial pressure, and TCD has been used to demonstrate excessive CBF
TABLE 2. Patient demographic and cardiopulmonary bypass data $(n=34)$

\begin{tabular}{lcc}
\hline & Mean \pm SD & Range \\
\hline Weight $(\mathrm{kg})$ & $3.2 \pm 0.7$ & $2.0-5.8$ \\
Age (d) & $13 \pm 23$ & $2-128$ \\
Cardiopulmonary bypass time (min) & $180 \pm 68$ & $69-348$ \\
Aortic crossclamp time (min) & $94 \pm 44$ & $0-239$ \\
DHCA time (min) & $19 \pm 16$ & $0-66$ \\
RLFP time (min) & $50 \pm 31$ & $6-158$ \\
\hline
\end{tabular}

under these conditions. ${ }^{17}$ Data from our study demonstrate that measurement of mean arterial pressure alone may be insufficient to protect against this potential problem. Newly available NIRS monitors (NIRO 300; Hamamatsu Photonics) that use four infrared wavelengths and specially resolved spectrometer technology ${ }^{13}$ and prototype frequency domain NIRS devices ${ }^{18}$ have the potential to accurately measure an absolute value for cerebral $\mathrm{So}_{2}$.

Compared with jugular venous bulb blood $\mathrm{So}_{2}$, the NIRS values tend to run high at low jugular venous bulb $\mathrm{So}_{2}$ and low at high jugular venous bulb $\mathrm{So}_{2}$ in children undergoing operations for congenital heart defects. ${ }^{9}$ This could lead to a situation during RLFP where bypass flow is unnecessarily increased to achieve a higher NIRS reading of cerebral $\mathrm{SO}_{2}$. Finally, the NIRS device only measures cerebral $\mathrm{So}_{2}$ in a small volume of frontal cerebral cortex in the path of the emitted infrared light, leaving other areas of the brain potentially vulnerable.

CBFV, as measured by TCD, also has its own limitations. TCD measures CBFV only and does not provide a 


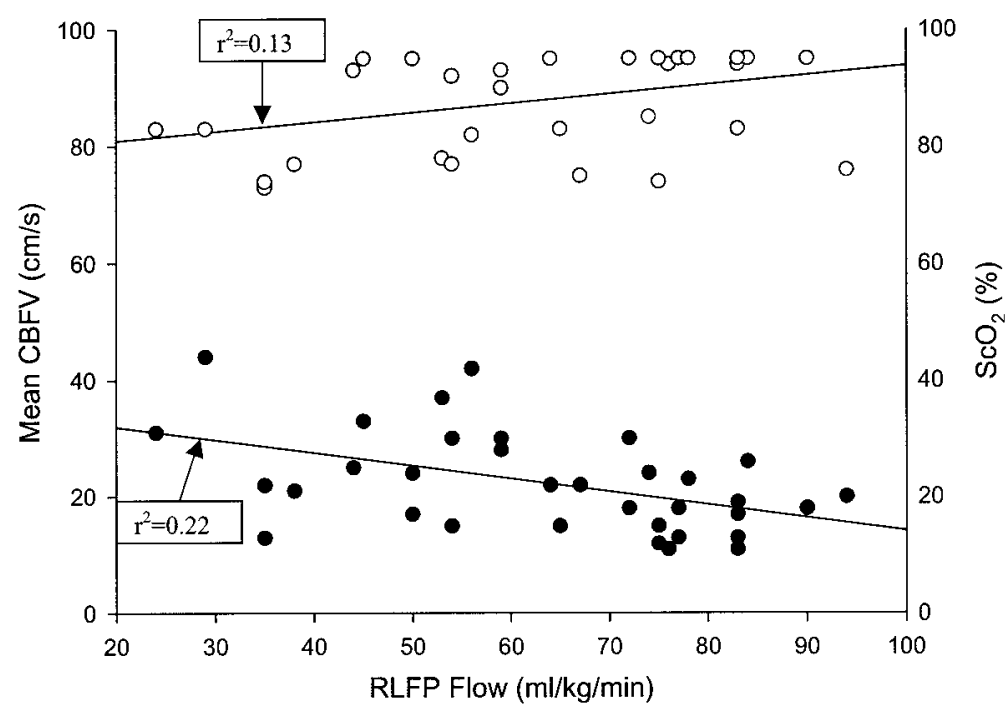

Figure 2. Mean CBFV (on left axis, filled circles) and cerebral $\mathrm{S}_{2}\left(\mathrm{ScO}_{2}\right)$ (on right axis, open circles) versus RLFP flow rate; $r^{2}$ values for linear regression analysis are displayed.

TABLE 3. Intraoperative perfusion and monitoring data $(n=34)$

\begin{tabular}{|c|c|c|c|}
\hline & $\begin{array}{l}\text { Baseline full cardiopulmonary } \\
\text { bypass flow }\left(17^{\circ} \mathrm{C}-22^{\circ} \mathrm{C}\right)\end{array}$ & $\begin{array}{l}\text { During low-flow cerebral } \\
\text { perfusion }\left(17^{\circ} \mathrm{C}-22^{\circ} \mathrm{C}\right)\end{array}$ & $\begin{array}{l}\text { After repair full } \\
\text { flow }\left(17^{\circ} \mathrm{C}-22^{\circ} \mathrm{C}\right)\end{array}$ \\
\hline $\begin{array}{l}\text { Mean arterial pressure, radial/brachial } \\
\text { artery }(\mathrm{mm} \mathrm{Hg})\end{array}$ & $34 \pm 4$ & $29 \pm 8^{*}$ & $34 \pm 5$ \\
\hline $\begin{array}{l}\text { Mean arterial pressure, umbilical/femoral } \\
\text { artery }(\mathrm{mm} \mathrm{Hg})\end{array}$ & $31 \pm 6$ & $12 \pm 4^{*}$ & $35 \pm 5 \dagger$ \\
\hline $\begin{array}{l}\text { Cardiopulmonary bypass flow } \\
(\mathrm{mL} /[\mathrm{kg} \cdot \mathrm{min}])\end{array}$ & $153 \pm 8$ & $63 \pm 19^{*}$ & $158 \pm 17$ \\
\hline CBFV $(\mathrm{cm} / \mathrm{s})$ & $22 \pm 10$ & $22 \pm 9$ & $20 \pm 8$ \\
\hline Cerebral $\mathrm{SO}_{2}(\%)$ & $87 \pm 9$ & $88 \pm 8$ & $86 \pm 9$ \\
\hline Calculated base excess & $+1.0 \pm 3.0$ & $+0.1 \pm 2.2^{*}$ & $-1.5 \pm 2.8 \dagger$ \\
\hline Lactate $(\mathrm{mmol} / \mathrm{L}), \mathrm{n}=19$ & $3.0 \pm 1.9$ & $3.4 \pm 1.8^{*}$ & $4.3 \pm 1.6 \dagger$ \\
\hline Hematocrit (\%) & $25 \pm 3$ & $24 \pm 3$ & $24 \pm 3$ \\
\hline $\mathrm{pH}$ (temperature corrected) & $7.49 \pm 0.09$ & $7.52 \pm 0.06 \ddagger$ & $7.44 \pm 0.09 \dagger$ \\
\hline $\mathrm{PCO}_{2}$ (temperature corrected) & $30 \pm 7$ & $26 \pm 4^{*}$ & $31 \pm 7$ \\
\hline
\end{tabular}

Results expressed as mean \pm SD.

${ }^{*} P<.05$ versus baseline and postrepair values, 1-way analysis of variance.

$\dagger P<.05$ versus baseline value, 1-way analysis of variance.

$\ddagger P<.05$ versus postrepair value, 1 -way analysis of variance.

direct measure of blood flow. However, CBFV is directly proportional to total blood flow if cerebral vascular resistance and perfusion pressure are constant. These conditions were met during the hypothermic bypass data collection phase of this study. TCD also measures flow in only one cerebral artery and thus could potentially leave hypoperfusion undetected in other areas of the brain.

In addition to cerebral $\mathrm{So}_{2}$, the Somanetics cerebral oximeter can display a relative CBVI. This is an index that reflects total cerebral intravascular hemoglobin, as deter- mined by the change in absorbence at $810 \mathrm{~nm}$, which is the isosbestic point for oxygenated and deoxygenated hemoglobin. ${ }^{19}$ Pigula and colleagues ${ }^{6}$ have described the use of $\mathrm{CBVI}$ along with cerebral $\mathrm{So}_{2}$ to guide bypass flow during RLFP. CBVI may reflect actual cerebral blood volume only if hemoglobin concentration does not change; however, there has been no reported validation of this measurement. In addition, the CBVI is displayed as an index without a numeric readout on a scale that is difficult to read because of its small size. For these reasons we did not attempt to 
correlate CBVI with TCD measurements, and we believe that the addition of CBFV measurement provides important additional information during RLFP.

In Pigula and colleagues' study, ${ }^{6}$ a bypass flow of only $20 \mathrm{~mL} /(\mathrm{kg} \times \mathrm{min})$ was necessary to restore cerebral $\mathrm{So}_{2}$ and CBVI to baseline levels. This contrasts with the average value of $63 \mathrm{~mL} /(\mathrm{kg} \times \mathrm{min})$ for our patients, with flows as high as $94 \mathrm{~mL} /(\mathrm{kg} \times \mathrm{min})$. Despite these higher flows, the surgical field remained bloodless in all patients in our study during the arch reconstruction. There are several reasons for this discrepancy. First, Pigula and colleagues ${ }^{6}$ used the alpha-stat blood gas management, which may lead to relatively less CBF and volume even at hypothermic temperatures. We used the $\mathrm{pH}$-stat strategy because of recent human and experimental animal evidence that neurologic outcome is improved relative to the alpha-stat strategy. ${ }^{20,21}$ Decreased cerebral vascular resistance with this strategy may require higher blood flows and volumes. Second, every patient in our study received either phenoxybenzamine or phentolamine hydrochloride, potent $\alpha$-receptor antagonists that dilate the cerebral vasculature. Third, although our cannulation technique was identical to that of Pigula and colleagues $^{6}$ for patients undergoing the Norwood operation, 19 of our 34 patients underwent aortic arch advancement without snares on the brachiocephalic vessels or opening of the proximal aortic arch. The left subclavian artery and left carotid artery were also perfused during the latter technique, because the descending aortic crossclamp was applied distal to them. Therefore in some cases we potentially perfused additional vascular beds; however, the lack of difference in RLFP flow between patients who underwent Norwood procedures and those who did not argues against this. The need for higher flows during RLFP relative to previous studies is also consistent with our institutional strategy of high-flow, low-pressure, vasodilated perfusion throughout cardiopulmonary bypass because of the theoretic advantages associated with this practice of improved end-organ function and less capillary leakage. We also sought to duplicate the prebypass, steady-state CBFV for each patient. Finally, although this was not addressed in our study, higher RLFP rates may provide higher blood flow to the lower body through collateral circulation, potentially increasing oxygen delivery to the subdiaphragmatic vascular beds and improving organ function.

One important finding of our study is that the pressure measured in the radial or brachial artery during RLFP had no correlation with the bypass flow required for adequate cerebral perfusion and oxygenation. Similarly, both cerebral $\mathrm{SO}_{2}$ and pump flow rate had a poor correlation with the CBFV during RLFP. Thus increasing bypass flow to a target pressure, cerebral $\mathrm{SO}_{2}$, or predetermined flow rate, without another monitor of cerebral perfusion, could lead to inadequate or excessive CBF.
We demonstrated, as have Pigula and coworkers, ${ }^{14}$ that RLFP results in a significant pressure detected in the umbilical or femoral artery. The presumed reason for this somatic circulatory support during RLFP is the extensive network of arterial collaterals in the neonate, from vessels such as the internal thoracic and intercostal arteries that connect to the arterial supply of the subdiaphragmatic viscera. ${ }^{14}$ However, our patients had significant increases in lactate and calculated base deficit during RLFP. This is not explained by addition of banked blood with elevated lactate concentration to the bypass circuit, because none of our patients received additional blood during the period of hypothermia. Thus inadequate oxygen delivery to some tissue beds of a severity to cause lactic acidosis developed during RLFP. This would predictably be worse if these vascular beds were subjected to DHCA.

In conclusion, this study demonstrates that $\mathrm{CBFV}$, as measured by TCD, is a useful addition to cerebral $\mathrm{So}_{2}$, as measured by NIRS, in guiding bypass flow during RLFP. We did not compare TCD used together with NIRS against NIRS alone in guiding RLFP and thus did not prove one method superior to the other; a randomized controlled study would be necessary to answer that question. TCD provides information that NIRS alone cannot, specifically an independent, validated method of estimating CBF with an easily readable numeric display and waveform. The addition of TCD to NIRS monitoring during RLFP may increase the safety and accuracy of this technique by avoiding excessive $\mathrm{CBF}$.

We thank Debora East, RN, for assistance with data collection, Barbara Skjonsby, RN, for editorial assistance, and E. O'Brian Smith, PhD, for statistical consultation.

\section{References}

1. Newberger JW, Jonas RA, Wernovsky G, Wypij D, Hickey PR, Kuban KC, et al. A comparison of the perioperative effects of hypothermic circulatory arrest versus low flow cardiopulmonary bypass. N Engl J Med. 1993;329:1057-64.

2. Hickey PR. Neurologic sequelae associated with deep hypothermic circulatory arrest. Ann Thorac Surg. 1998;65(6 Suppl):S65-9.

3. Rebeyka IM, Coles JG, Wilson GJ, Watanabe T, Taylor MJ, Adler SF, et al. The effect of low-flow cardiopulmonary bypass on cerebral function: an experimental and clinical study. Ann Thorac Surg. 1987; 43:391-6.

4. Asou T, Kado H, Imoto Y, Shiokawa Y, Tominaga R, Kawachi Y, et al. Selective perfusion technique during aortic arch repair in neonates. Ann Thorac Surg. 1996;61:1546-8.

5. Pigula FA, Siewers RD, Nemoto EM. Regional perfusion of the brain during neonatal aortic arch reconstruction. J Thorac Cardiovasc Surg. 1999;117:1023-4.

6. Pigula FA, Nemoto EM, Griffith BP, Siewers RD. Regional low-flow perfusion provides cerebral circulatory support during neonatal aortic arch reconstruction. J Thorac Cardiovasc Surg. 2000;119:331-9.

7. Wardle SP, Yoxall CW, Weindling AM. Cerebral oxygenation during cardiopulmonary bypass. Arch Dis Child. 1998;78:26-32.

8. Daubeney PE, Smith DC, Pilkington SN, Lamb RK, Monro JL, Tsang VT, et al. Cerebral oxygenation during paediatric cardiac surgery: identification of vulnerable periods using near infrared spectroscopy. Eur J Cardiothorac Surg. 1998;13:370-7. 
9. Daubeney PE, Pilkington SN, Janke E, Chalrton GA, Smith DC, Webber SA. Cerebral oxygenation measured by near-infrared spectroscopy: comparison with jugular bulb oximetry. Ann Thorac Surg. 1996;61:930-4.

10. Burrows FA. Transcranial Doppler monitoring of cerebral perfusion during cardiopulmonary bypass. Ann Thorac Surg. 1993;56:1482-4.

11. Zimmerman AA, Burrows FA, Jonas RA, Hickey PR. The limits of detectable cerebral perfusion by transcranial Doppler sonography in neonates undergoing deep hypothermic low-flow cardiopulmonary bypass. J Thorac Cardiovasc Surg. 1997;114:594-600.

12. Austin EH, Edmonds HL, Auden SM, Seremet V, Niznik G, Sehic A, et al. Benefit of neurophysiologic monitoring for pediatric cardiac surgery. J Thorac Cardiovasc Surg. 1997;114:707-17.

13. Yoshitani K, Kawaguchi M, Tatsumi K, Kitagucuchi K, Furuya H. A comparison of the INVOS 4100 and the NIRO 300 near-infrared spectrophotometers. Anesth Analg. 2002;94:586-90.

14. Pigula FA, Gandhi SK, Siewers RD, Davis PJ, Webber SA, Nemoto EM. Regional low-flow perfusion provides somatic circulatory support during neonatal aortic arch surgery. Ann Thorac Surg. 2001;72: 401-7.

15. Reddy VM, Hanley FL. Cardiac surgery in infants with very low birth weight. Semin Pediatr Surg. 2000;9:91-5.

16. Biehl DA, Stewart DL, Forti NH, Cook LN. Timing of intracranial hemorrhage during extracorporeal life support. ASAIO J. 1996;42: 938-41.

17. Van de Bor, Walther FJ, Gangitano ES, Snyder JR. Extracorporeal membrane oxygenation and cerebral blood flow velocity in newborn infants. Crit Care Med. 1990;18:10-3.

18. Kurth CD, Steven JL, Montenegro LM, Watzman HM, Gaynor JW, Spray TL, et al. Cerebral oxygen saturation before congenital heart surgery. Ann Thorac Surg. 2001;72:187-92.

19. Kurth CD, Steven JM, Nicolson SC, Chance B, Delivoria-Papadopoulos M. Kinetics of cerebral deoxygenation during deep hypothermic circulatory arrest in neonates. Anesthesiology. 1992;77:656-61.

20. Priestly MA, Golden JA, O'Hara IB, McCann J, Kurth CD. Comparison of neurologic outcome after deep hypothermic circulatory arrest with alpha-stat and $\mathrm{pH}$-stat cardiopulmonary bypass in newborn pigs. J Thorac Cardiovasc Surg. 2001;121:336-43.

21. du Plessis AJ, Jonas RA, Wypij D, Hickey PR, Riviello J, Wessel DL, et al. Perioperative effects of alpha-stat versus $\mathrm{pH}$-stat strategies for deep hypothermic cardiopulmonary bypass in infants. J Thorac Cardiovasc Surg. 1997;114:991-1001.

\section{Discussion}

Dr Frank A. Pigula (Pittsburgh, $\mathrm{Pa}$ ). In this study Andropoulos and colleagues have evaluated TCD as a means of regulating RLFP in neonates and infants undergoing arch reconstruction. I think that this is an interesting study because it expands on the discussion of the regulation of regional perfusion, which to my mind is a critical issue in the safe and successful application of this technique.

In this study data were collected before, during, and after regional perfusion under similar conditions, with the goal of maintaining cerebral $\mathrm{SO}_{2}$ and $\mathrm{CBFV}$ within $10 \%$ of baseline values. With this approach, Andropoulos and colleagues reported that regional perfusion was able to maintain measurable blood pressures both above and below the diaphragm while maintaining cerebral $\mathrm{SO}_{2}$ at baseline levels.

Dr Fraser, your rationale for the use of TCD is that under hypothermic conditions NIRS may overestimate RLFP requirements, leading to cerebral hyperperfusion and brain injury. You correctly point out that NIRS measures cerebral $\mathrm{So}_{2}$ only to $95 \%$. When you used the TCD to guide your regional perfusion rates, 13 of the 34 patients had cerebral $\mathrm{So}_{2}$ of $95 \%$ during RLFP. In relying on the CBFV to manage regional perfusion rates, more than a third of your patients were at risk for the complication of concern, cerebral hyperperfusion.

I have a few questions. First, how did the TCD data alter your perfusion management? Did you reduce regional perfusion rates for cerebral $\mathrm{So}_{2}$ of $95 \%$ ?

Second, you stated in the article that $\mathrm{CBFV}$ and cerebral $\mathrm{SO}_{2}$ were maintained within $10 \%$ of baseline values. Which variable did you consider most important to maintain?

Third, you presumably collected relative blood volume data as well as $\mathrm{So}_{2}$ data with NIRS, and it would be of interest to know what the relative CBVI was for these patients and how it correlated with the TCD data.

Finally, in the article you stated that CBFV, as measured by TCD, provides information that NIRS alone cannot. Can you elaborate and be more specific on the advantages of TCD?

Dr Fraser. Thank you, Dr Pigula. You have certainly been a leader in the investigation of this methodology, and we took a lot of our direction from your pioneering work. We are grateful for your insight into this study.

Our questions actually arose from my concerns about the use of this technique, having grown up with circulatory arrest as sort of the standard. I was quite concerned and actually somewhat reluctant to take this on, for the very reasons to which you alluded, that there is a significant potential for hypercirculation to the brain. Through the investigation of your work and that of others, we came to believe that the CBVI, in addition to the NIRS cerebral $\mathrm{SO}_{2}$ data, was inadequate for us to be sure that we were not overperfusing the brain.

In a practical sense, we found the CBVI readout on the NIRS monitor difficult to follow. There are no units associated with it. As you know, it is not really a Food and Drug Administrationapproved measurement. And we are not really sure what it means, because it actually can vary somewhat depending on the patient hematocrit. So to follow the CBVI one must be quite confident that the hematocrit is staying the same during the whole period. Of course, it often is during this procedure, but we did not consider it was sufficiently certain. Because we had been using TCD for other reasons in our patients, sharing cannula position and venous drainage, it seemed like a natural extension for us.

In fact, for those patients you mentioned with NIRS values of $95 \%$, it is hard to know what that means. I think that in those cases individually we did vary flows on the basis of TCD data, most commonly to decrease the flow.

Dr Erle H. Austin III (Louisville, Ky). I congratulate you on your decision to use intraoperative neuromonitoring in this group, as well as on your excellent clinical results. I would quibble with you a little bit about the word novel in the title of your article. We have been using a combination of TCD and NIRS on a routine basis for infants undergoing heart surgery since 1994, and we actually reported on our initial experience with its use at this meeting in 1997.

We believe that both modalities do provide complementary information that neither technique can provide on its own. We do use these techniques routinely, and we have also found them useful in infants who undergo selective antegrade cerebral perfusion for procedures on the aortic arch, as you have presented here. We have 
had experience with 20 patients during the past 2 years. We use the TCD to tell us when we have established antegrade cerebral flow and to warn us when there is too much $\mathrm{CBF}$, as you have done.

In 14 of those 20 patients, we actually detected an abnormality with the TCD, with the flow being too high, too low, or even absent. These findings resulted in an alteration in our pump flow or repositioning of the arterial cannula. In 6 cases with no abnormal- ity in the TCD flow there was an abnormality or a significant desaturation found with the NIRS oximeter. In these cases we were able to correct the abnormality by increasing pump flow or making some kind of a change in hematocrit or $\mathrm{pH}$. So simply put, our experience in Louisville in many ways reflects yours and further supports the value of multimodality intraoperative neurophysiologic monitoring in infants undergoing heart surgery.

\section{ON THE MOVE?}

Don't miss a single issue of the journal! To ensure prompt service when you change your address, please photocopy and complete the form below.

Please send your change of address notification at least six weeks before your move to ensure continued service. We regret we cannot guarantee replacement of issues missed due to late notification.

\section{JOURNAL TITLE:}

Fill in the title of the journal here.

\section{OLD ADDRESS:}

Affix the address label from a recent issue of the journal here.

\section{NEW ADDRESS:}

Clearly print your new address here.

Name

Address

City/State/ZIP

\section{COPY AND MAIL THIS FORM TO:}

Mosby

Subscription Customer Service

6277 Sea Harbor Dr

Orlando, FL 32887
OR FAX TO:

407-363-9661

NM Mosby
OR PHONE:

800-654-2452

Outside the U.S., call

407-345-4000 